\title{
Influence of spironolactone on neonatal screening for congenital adrenal hyperplasia
}

\author{
Itaru Terai, Kimiaki Yamano, Naoshi Ichihara, Junri Arai, Kunihiko Kobayashi
}

\begin{abstract}
Aim-To determine if the diuretic spironolactone cross reacts with $17 \alpha-$ hydroxyprogesterone (17OHP) in an enzyme linked immunosorbent assay (ELISA) kit used for the mass screening of congenital adrenal hyperplasia.

Methods-Concentrations of 17OHP on a blood filter paper disc were measured using an ELISA kit (kit C-7: ENZAPLATE N-17 -OHP-7; Chiron, Tokyo, Japan). The cross reactivity of spironolactone and its metabolites with $17 \mathrm{OHP}$ was determined. The concentrations of spironolactone and its metabolites in blood were measured using HPLC (high performance liquid chromatography).

Results-Spironolactone cross reacted with 17OHP using kit C-7 (0.01\%), by increasing $17 \mathrm{OHP}$ concentration in a dose dependent manner. The blood concentration of spironolactone and its metabolites was nearly $900 \mathrm{ng} / \mathrm{ml}$, high enough to show an additive effect on the 17OHP concentration. About $12 \%$ of the false positive cases screened using the kit were due to the administration of spironolactone.

Conclusions-Spironolactone interferes with 17OHP concentrations, leading to false positive test results for CAH.
\end{abstract}

(Arch Dis Child Fetal Neonatal Ed 1999;81:F179-F183)

Keywords: screening; congenital adrenal hyperplasia; $17 \alpha$-hydroxyprogesterone; spironolactone

Neonates are screened for congenital adrenal hyperplasia using an enzyme linked immunosorbent assay (ELISA) or a radioimmunoassay for $17 \alpha$-hydroxyprogesterone (17OHP) on a blood filter paper disc. ${ }^{1-4}$

In Japan most screening samples are obtained between days 4 and 7 of life, and $17 \mathrm{OHP}$ on blood filter paper is measured using an ELISA at an officially designated local laboratory..$^{5-7}$ At present, any of the four commercially available kits-kit C-7, kit C-3, kit $\mathrm{E}$, or kit $\mathrm{K}$-are used in Japan. We use kit C-7. The blood specimen is assayed initially without extraction by organic solvent (direct assay); when an initial result is above the cutoff level, the same sample is usually rechecked using the same procedure, and simultaneously extracted by diethyl ether and measured again (extraction assay) using the ELISA. This is because diethyl ether extraction rarely identifies hydrophilic steroids such as $17 \alpha$-hydroxypregnenolone-3-sulphate ${ }^{8-10}$ and dehydroepiandrosterone sulphate, ${ }^{11-13}$ which are released in the blood of premature babies and/or stressed babies, and so this procedure reduces the frequency of false positive test results. $^{8} 111214$

Like most Japanese laboratories, we have adopted two concomitant cutoff levels: the percentile and the absolute value of 17OHP. We use the 95th percentile for direct assays. The cutoff level for the extraction assay is set at $3.5 \mathrm{ng} / \mathrm{ml}(10.6 \mathrm{nmol} / \mathrm{l})$ blood. When the $17 \mathrm{OHP}$ concentration in the first sample measured by direct assay shows remarkably high values (more than $30 \mathrm{ng} / \mathrm{ml}(90.8 \mathrm{nmol} / \mathrm{l})$ for the infant weighing more than $2000 \mathrm{~g}$ ), the extraction assay is omitted, and the baby is promptly referred to the paediatric specialist at the hospital. Cases with high $17 \mathrm{OHP}$ values by extraction assay are also referred without delay, while those with slightly raised concentrations are requested to return for a second sampling. ${ }^{5-7}$

Many of the repeat specimens were from infants with congenital heart disease who were receiving diuretics and digoxin. We suspected that spironolactone, a diuretic, and/or digoxin, both of which have a steroid structure, cross reacted with $17 \mathrm{OHP}$ in the $17 \mathrm{OHP}$ ELISA kit, producing a false positive result.

\section{Methods}

Dried blood spots on filter paper, taken at days 4 to 7 of life, for neonatal screening for inborn errors of metabolism, including congenital hypothyroidism and $\mathrm{CAH}$, were collected from the Hokkaido prefecture excluding Sapporo city. The study was carried out in accordance with the Helsinki declaration, with informed consent from the parents.

The concentration of $17 \mathrm{OHP}$ on filter paper blood spots was measured using an ELISA kit. For analysis, a $3 \mathrm{~mm}$ diameter disc was punched out from the inner circles of each blood spot area. Standards and controls provided in the kit consisted of dried blood spots with $17 \mathrm{OHP}$ of known concentrations. For the assay, the manufacturer's instructions were followed at all stages of the procedure. Namely, each filter disc was directly put into microtitration wells coated with goat antirabbit IgG antibody (direct assay method), and the reaction was started by the addition of $50 \mu \mathrm{l}$ horseradish peroxidase labelled 17OHP (17OHP-HRP conjugate) and $100 \mu \mathrm{l}$ rabbit antiserum specific for $17 \mathrm{OHP}$. The microtitre plate was covered with a plate seal and incubated for 18 hours at $25^{\circ} \mathrm{C}$. The discs were then removed and the plate was washed three times with the detergent provided in the kit. After removing the washing solution $150 \mu \mathrm{l}$ of colour coupler solution (hydrogen peroxide 
and o-phenylenediamine) were added into each well, and the plate was incubated at $25^{\circ} \mathrm{C}$ for 30 minutes in the dark. The reaction was stopped by the addition of $100 \mu$ termination solution, and the absorbency was read at 492 nm using a microplate reader (MTP-120, Corona electric Co., Katsuta, Japan). 17OHP concentrations were calculated using a computer programmed with the manufacturer's calculating software.

The extraction assay method was performed in duplicate using diethyl ether as an organic solvent. ${ }^{128}$ One filter disc ( $3 \mathrm{~mm}$ in diameter) containing dried blood was transferred to a test tube $(50 \mathrm{~mm} \times 6 \mathrm{~mm})$ containing deionised water $(200 \mu \mathrm{l})$, shaken vigorously for 6 minutes using a multi-tube vortexer, and then kept still overnight at room temperature. The $17 \mathrm{OHP}$ released into the water was extracted with diethyl ether $(1 \mathrm{ml})$ by mixing for 2 minutes and spinning at $3000 \mathrm{rpm}$ for 5 minutes at $4^{\circ} \mathrm{C}$. Separation of the organic phase was carried out by freezing the watery phase by means of a refrigerating mixture (dry ice and ethanol). The diethyl ether extract was transferred to another test tube, and the organic phase was completely evaporated to dryness by heating at $55^{\circ} \mathrm{C}$. Seventy five microlitres of peroxidase labelled 17OHP were added to the resultant residue, $50 \mu$ aliquots of which were subjected to the ELISA described above.

Compounds with a steroid structure, including spironolactone, digoxin, spironolactone metabolites, cortisol, dexamethasone, cortisone, prednisolone, and aldosterone dissolved in dimethylsulphoxide at $10 \mathrm{ng} / \mathrm{ml}$ were further diluted with methanol or water. Aliquots of steroid solutions at different concentrations were added in duplicate directly into the wells of the ELISA. The percentage cross reactivity was calculated at $50 \%$ displacement of the 17OHP-HRP conjugate. This experiment was performed with four commercially available $17 \mathrm{OHP}$ neonatal screening kits. For each assay, the respective manufacturer's instructions were followed. An additive effect of spironolactone to the $17 \mathrm{OHP}$ value in kit $\mathrm{C}-7$ was tested for on filter discs ( $3 \mathrm{~mm}$ in diameter) coated with a constant amount of $17 \mathrm{OHP}$, together with an increasing amount of spironolactone. Spironolactone, frusemide (also known as furosemide or Lasix), and digoxin were purchased from Wako Pure Chemical Industries, Ltd. (Osaka, Japan). Potassium canrenoate (Soldactone) was purchased from Searle (Skokie, ILL, USA). $\quad 7 \alpha$-thiomethylspironolactone, canrenone, and 6 $\beta$-hydroxy- $7 \alpha$-thiomethylspironolactone, which are the main metabolites of spironolactone, ${ }^{15}$ were kindly donated by Searle. Cortisol, dexamethasone, cortisone, prednisolone, and $\alpha$-aldosterone were purchased from Sigma Chemical Co. (MO, USA).

A quantitative analysis of spironolactone and its metabolites in dried blood spots on filter paper was accomplished by modifying the previously described method. ${ }^{16-19}$ One filter disc (10 $\mathrm{mm}$ in diameter) containing dried blood was immersed in $1 \mathrm{ml}$ of $0.05 \mathrm{M}$ phosphate buffer, $\mathrm{pH}$ 8.0, and sonicated for 10 minutes. Then, $10 \mathrm{ng}(30 \mu \mathrm{l})$ of 19 -nortestosterone in
$60 \%$ methanol was added to the solution as an internal standard, and the resultant mixture was applied to the Extrelut column 1 (Merck \& Co., Inc., Rahway, NJ, USA). Steroids adsorbed to the column were then eluted with dichloromethane (twice with $5 \mathrm{ml}$ ), and the eluate was completely evaporated to dryness by a nitrogen stream. The resultant residue was dissolved with $60 \mu \mathrm{l}$ of $60 \%$ methanol, $30 \mu \mathrm{l}$ aliquots of which were analysed by a reversed phase HPLC on an ERC-ODS-1171 column (ERMA CR, INC. Tokyo, Japan).

\section{Results}

When filter paper discs coated with increasing amounts of spironolactone with or without a constant amount of 17OHP (3.4 ng/ml $=10.3$ $\mathrm{nmol} / \mathrm{l}$ ) were measured for $17 \mathrm{OHP}$ by a direct assay using the ELISA kit C-7, 17OHP values rose according to the amount of spironolactone added (fig 1). The curves produced by spironolactone alone on the discs and by spironolactone with a constant amount of $17 \mathrm{OHP}$, parallelled each other, indicating the additive effect of spironolactone. The same phenomenon was also observed in the extract assay (not shown). Results suggested that spironolactone cross reacts with antibodies to $17 \mathrm{OHP}$ used in kit C-7. Percentage cross reactivity was determined for spironolactone and its metabolites using several different ELISA kits.

As shown in table 1, the cross reactivity of spironolactone with $17 \mathrm{OHP}$ in kit C-7 was calculated to be $0.01 \%\left(1.1 \times 10^{-2} \%\right)$, and those of its metabolites at the level of $10^{-3}$ to $10^{-5} \%$. In other kits (E, K, C-3), the percentage cross reactivity of spironolactone with $17 \mathrm{OHP}$ was in the order of $10^{-4}$ to $10^{-6}$-much lower concentrations than those obtained with kit C-7 (table 1). Cross reactivity of other steroids (cortisol, dexamethasone, cortisone, prednisolone, and aldosterone) in kit C-7 was at the level of $10^{-5}$ to $10^{-6} \%$ (data not shown), and no cross reactivity was found for digoxin and frusemide.

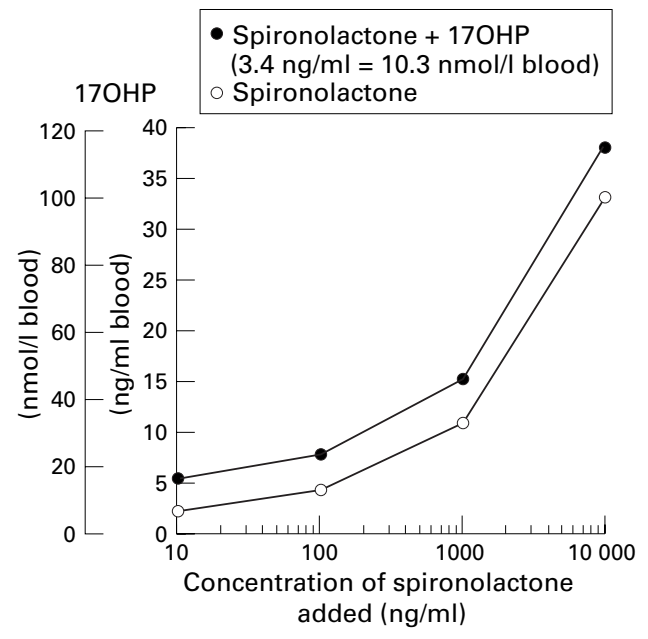

Figure 1 Additive effect of spironolactone plotted against the $17 O H P$ value in kit C-7 (direct assay): closed circles indicate $17 \mathrm{OHP}$ values obtained from filter discs coated with increasing amounts of spironolactone and a constant amount of $17 \mathrm{OHP}$ (3.4 $\mathrm{ng} / \mathrm{ml}$ or $10.3 \mathrm{nmol} / \mathrm{l} \mathrm{blood})$. 
Table 1 Cross reactivity of spironolactone and its metabolites with 17OHP

\begin{tabular}{lllll}
\hline Steroid & Kit $C-7$ & Kit $C-3$ & Kit $E$ & Kit K \\
\hline Spironolactone & $1.1 \times 10^{-2}(\%)$ & $1.6 \times 10^{-6}$ & $1.3 \times 10^{-4}$ & $1.7 \times 10^{-4}$ \\
Canrenoate & $1.2 \times 10^{-5}$ & $1.1 \times 10^{-6}$ & $1.9 \times 10^{-7}$ & $1.4 \times 10^{-5}$ \\
Canrenone & $3.0 \times 10^{-4}$ & $\mathrm{ND}^{\star}$ & $3.2 \times 10^{-6}$ & $\mathrm{ND}$ \\
$7 \alpha$-Thiomethylspironolactone & $6.2 \times 10^{-3}$ & $\mathrm{ND}$ & $1.8 \times 10^{-5}$ & $\mathrm{ND}$ \\
$6 \beta$-Hydroxy-7 $\alpha$-thiomethylspironolactone & $2.5 \times 10^{-5}$ & $\mathrm{ND}$ & $1.1 \times 10^{-6}$ & $\mathrm{ND}$ \\
\hline
\end{tabular}

^Not done

CASE REPORTS

Case 1 (fig 2)

A boy born by normal vaginal delivery at 39 weeks and weighing $3308 \mathrm{~g}$ was discharged on day 5 . Although screening at day 5 for $\mathrm{CAH}$ was normal, with a value of $3.7 \mathrm{ng} / \mathrm{ml}(11.2$ $\mathrm{nmol} / \mathrm{l}$ ) 17OHP by direct assay, the screening result for galactosaemia was slightly positive. A second sample of blood for galactosaemia was obtained on day 13. Subsequent to discharge, the infant developed a cough and severe oedema due to congestive heart failure arising from a ventricular septal defect, and was treated with frusemide, spironolactone, and digoxin. Figure 2 shows that before treatment, the $17 \mathrm{OHP}$ concentration by direct assay in kit C-7 showed a slight increase, but that by extraction assay it was within normal limits. This initial increase in $17 \mathrm{OHP}$ was considered to be due to some hydrophilic steroid released by the stress of the congestive heart failure. However, two days after the administration of the drugs, the 17OHP concentration became very high in both direct and extraction assays. After the administration of diuretics, the patient progressed satisfactorily, and $17 \mathrm{OHP}$ concentration decreased gradually. This decrease coincided with the decrease in spironolactone per weight per day (mg/kg/day) (fig 2). From the same sample, 17OHP was also measured by kits $\mathrm{E}$ and $\mathrm{C}-3$, by direct assay. In kit $\mathrm{E}$, an abnormally high $17 \mathrm{OHP}$ value was noted when congestive heart failure was at its peak, before the administration of diuretics. However, the values decreased as the condition improved with the administration of diuretics. This abnormal 17OHP peak coincided with the transient increase in body weight due to congestive heart failure during the course of overall weight loss (fig 2 ). The extraction assay using kit $\mathrm{E}$, however, showed that every concentration was within normal limits. A similar result was obtained with kit C-3 (not shown). These results indicate that, in the direct assay, both kits $\mathrm{E}$ and $\mathrm{C}-3$ pick up some hydrophilic steroids which are probably released into the blood as a result of severe stress.

Case 2 (fig 3)

A boy born at 39 weeks and weighing $3064 \mathrm{~g}$ had a complex coarctation of aorta. Spironolactone was administered soon after the birth, the dose increasing in proportion to his weight gain. In this case, $17 \mathrm{OHP}$ values measured by kit C-7 in both direct and extraction assays remained high during the administration of spironolactone but decreased to normal once the drug was stopped. Using kits E and C-3 (data not shown) in both direct and extraction assays, the time course changes in $17 \mathrm{OHP}$ concentrations parallelled those seen with kit
C-7, although every value remained within normal limits.

Case 3 (fig 4)

A boy born at 29 weeks of gestation and weighing $1310 \mathrm{~g}$ at birth received frusemide for oedema due to immaturity of the kidney. The $17 \mathrm{OHP}$ concentration showed a slight increase by direct assay and a normal value by extraction assay in kit C-7. After the baby began treatment with spironolactone, the concentrations of $17 \mathrm{OHP}$ by both assay methods increased parallel to each other and exceeded the cutoff level, but returned to normal once spironolactone was withdrawn. By contrast, $17 \mathrm{OHP}$ concentration, measured by direct assay in kit $\mathrm{E}$ before treatment, was noticeably increased, although the extraction assay value was within normal limits. This initial increase in $17 \mathrm{OHP}$ by kit $\mathrm{E}$ was considered to be due to some hydrophilic steroid secreted in premature infants. Using kits E and C-3 (data not shown) following extraction assay, all $17 \mathrm{OHP}$ values remained within the normal range, and their
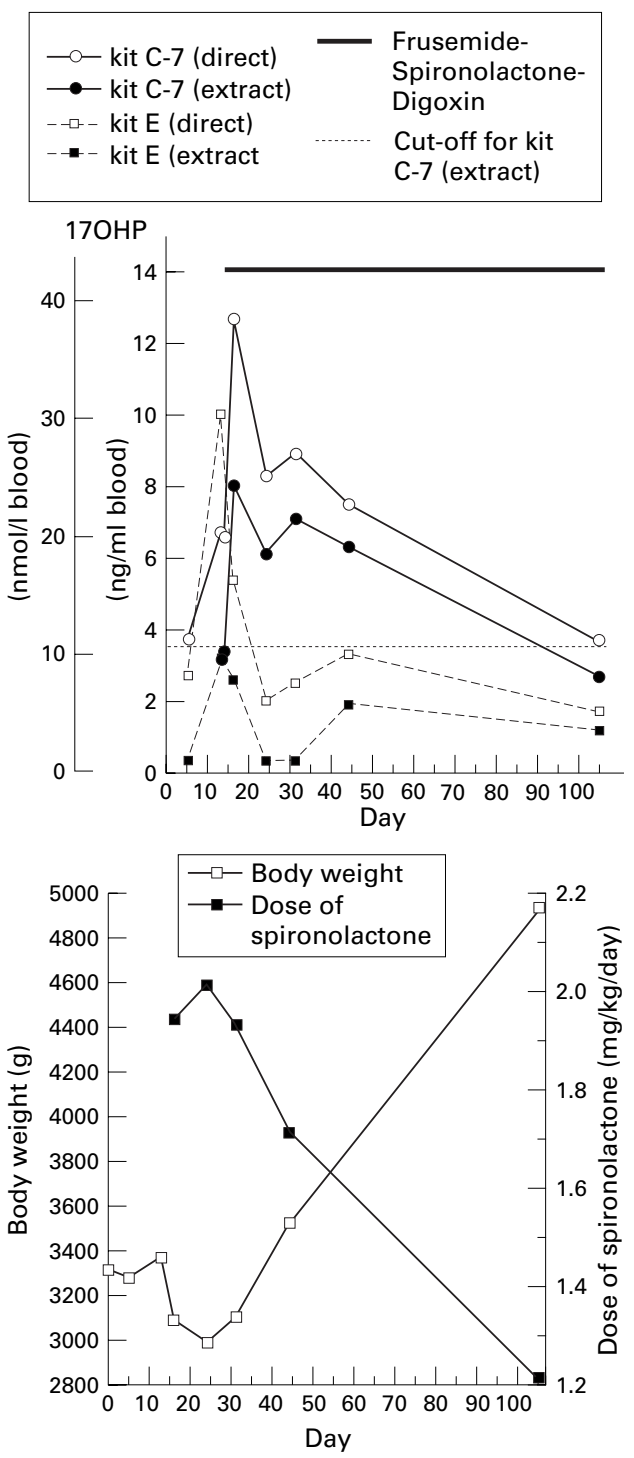

Figure 2 Clinical course of case 1 showing correlation between spironolactone and $170 H P$ concentration. 
time course changes parallelled those obtained with kit C-7.

Concentrations of spironolactone metabolites in a $\mathrm{CAH}$ false positive case (case 1) were measured by HPLC using blood spots on filter paper. Although 17OHP was below the detectable level, spironolactone and its major derivatives, $7 \alpha$-thiomethylspironolactone, canrenone, and $6 \beta$-hydroxy- $7 \alpha$-thiomethylspironolactone, were detected at 32, 575, 153 and $132 \mathrm{ng} / \mathrm{ml}$ blood, respectively. This indicates that nearly $900 \mathrm{ng} / \mathrm{ml}$ in gross concentration of spironolactone and its metabolites were present in the patient's blood.

From 1 April 1996 to 31 March 1997, the total number of tested cases for $\mathrm{CAH}$ was 33938. The number of cases identified as false positive was 235 , of which $29(12.3 \%)$ were found to have been treated with spironolactone. Fourteen of the 29 cases had congenital heart disease, and the remaining 15 cases were mostly low birthweight infants.
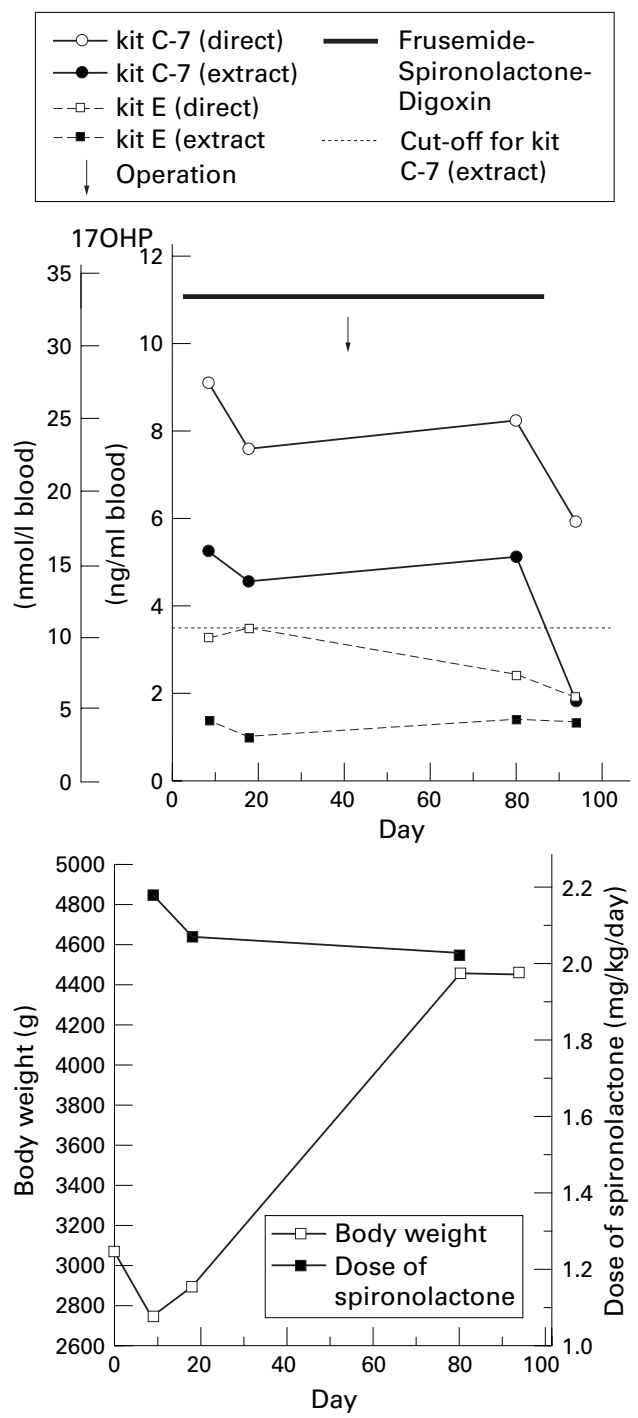

Figure 3 Clinical course of case 2 showing that $170 H P$ values were consistently high during treatment with spironolactone and fell once treatment was stopped.
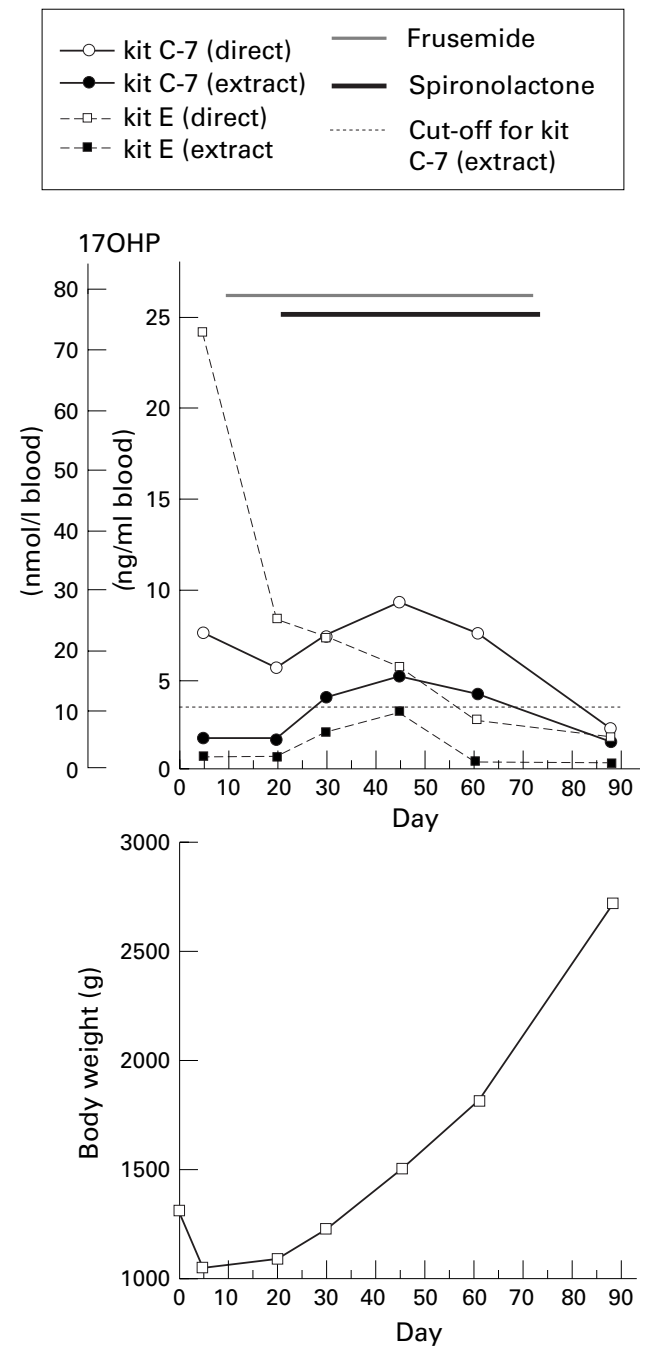

Figure 4 Clinical course of case 3 showing correlation between concentrations of $17 \mathrm{OHP}$ and treatment with spironolactone.

\section{Discussion}

Determination of 17OHP in dried blood spots by ELISA is used as the initial screening test for $\mathrm{CAH}$. Although the assay is sensitive and reproducible, the specificity is not sufficient to differentiate true positive patients with $\mathrm{CAH}$ from false positive cases associated with prematurity $^{1-5}{ }^{11}$ and/or stress. ${ }^{12}{ }^{14}$ In general, aside from the above cited causes, relatively high $17 \mathrm{OHP}$ values of unknown origin were often observed as most were noted to be transitory. It has been suggested that false positivity under these circumstances could be related to certain drugs, including steroids, which immunologically cross react with $17 \mathrm{OHP}$ in the assay system. This report documents that, at least in some of the false positive cases, the cause is due to spironolactone, which cross reacts with $17 \mathrm{OHP}$ in the assay. With kit C-7, 17OHP exceeded the cutoff level when the babies were administered therapeutic amounts of spironolactone and returned to normal when the drug dose was reduced or withdrawn. In contrast, assays using kits $\mathrm{E}$ or kit C-3, did not detect the false positive cases due to spironolactone, whereas premature babies or babies with severe stress showed false positive test results in direct 
assay, possibly due to a cross reaction with hydrophilic steroids.

A gross concentration of spironolactone and its metabolites $(900 \mathrm{ng} / \mathrm{ml}$ ) was detected by HPLC in the blood on filter paper from a patient who had been treated with spironolactone. This observation is compatible with a previous report indicating that the total serum concentration of spironolactone and its metabolites reaches 1000 $\mathrm{ng} / \mathrm{ml}$ several hours after administration of a single oral dose of $200 \mathrm{mg}$ spironolactone given to men weighing $65-87 \mathrm{~kg}$ (mean dose: $2.6 \mathrm{mg} / \mathrm{kg}$ weight). ${ }^{15}$ Ordinarily, the percentage of cross reactivity less than $0.01 \%$ between $17 \mathrm{OHP}$ and spironolactone and its metabolites in kit C-7 is negligible. However, in this study an actual additive effect of spironolactone on the value of $17 \mathrm{OHP}$ was observed with the drug blood concentration at more than $10 \mathrm{ng} / \mathrm{ml}$ (fig 1). This indicates that if the blood concentration of spironolactone exceeds $10 \mathrm{ng} / \mathrm{ml}$, it seems to affect the 17OHP concentration, especially in the extraction assay, where lipophilic compounds such as spironolactone and its metabolites, canrenone and sulphur containing intermediate metabolites, ${ }^{20}$ are preferentially extracted.

In almost all cases tested with kits $\mathrm{E}$ and $\mathrm{C}-3$ using the extraction assay, including the three patients reported above, the time course changes of the apparent 17OHP concentration parallelled those obtained with kit C-7, although the values obtained with the former two kits remained within the normal range. This observation indicates that spironolactone and its metabolites also interfere with $17 \mathrm{OHP}$ concentration, to some extent, in kits other than kit C-7.There may be other kits with characteristics similar to those of kit C-7, and this should be made known to laboratories using $17 \mathrm{OHP}$ neonatal screening kits.

Spironolactone and its metabolites, canrenone and canrenoate, can inhibit $11 \beta$ hydroxylase and 18-hydroxylase, possibly leading to the increase in blood concentration of $17 \mathrm{OHP} .^{21-24}$ However, this hypothesis seems unlikely as assay kits other than kit C-7 did not exhibit high concentrations of $17 \mathrm{OHP}$ in cases receiving spironolactone. In our study, about $12 \%$ of the false positive cases were identified as being due to the administration of spironolactone.

The above mentioned phenomena had not been identified at the developmental phase of this kit, but were found for the first time after a long time in use. Of course, the ELISA for CAH neonatal screening by kit C-7 is not used worldwide. However, every antibody used in currently available kits for $\mathrm{CAH}$ neonatal screening worldwide is not strictly specific for $17 \mathrm{OHP}$. Reduction of the false positive rate definitely depends on antibody specificity but not on the procedures such as EIA (enzyme immunoassay), FIA (fluoroimmunoassay), or RIA (radioimmunoassay), which are used worldwide. In this context, there must be situations where certain drugs or substances present in blood at high concentrations may interfere with the assay and lead to false positive screening results.
We thank Mrs M Inoue and Mrs R Hayashi (Hokkaido Institute of Public Health) for their technical skill and useful advice and Dr T Miura (College of Medical Technology, Hokkaido University) for his kind advice and helpful opinions. We also express our gratitude to Dr M Mikawa (Kitami Red Cross Hospital) and Dr A Tame (Obihiro Kyoukai Hospital) for their useful information about patients.

1 Piazzi S, Capelli M, Paolini M, et al. Neonatal screening for 21-hydroxylase deficiency: a microfilter paper method for 17- $\alpha$-hydroxyprogesterone assay. $\mathcal{f}$ Endocrinol Invest 1982;5:87-90.

2 Arakawa H, Maeda M, Tsuji A, Naruse H, Suzuki E, Kambegawa A. Fluorescence enzyme immunoassay of 17 $\alpha$-hydroxyprogesterone in dried blood samples of filter paper and its application to mass screening for congenital paper and its application to mass screening for congenital

3 Pang S, Wallace MA, Hofman L, et al. Worldwide experience in newborn screening for classical congenital adrenal hyperplasia due to 21-hydroxylase deficiency. Pediatrics 1988;81:866-74.

4 Pang S, Clark A. Congenital adrenal hyperplasia due to 21 hydroxylase deficiency: Newborn screening and its relationship to the diagnosis and treatment of the disorder. Screening 1993;2:105-39.

5 Naruse H, Suzuki E, Irie M, et al. Neonatal screening for congenital adrenal hyperplasia in Japan. Ann N Y Acad Sci 1985;458:103-10.

6 Suwa S. Commentary on neonatal mass-screening for congenital adrenal hyperplasia in Japan. Screening 1993;2:229-30

7 Suwa S. Worldwide and Japanese update of neonatal mass screening for congenital adrenal hyperplasia. In: Takasugi $\mathrm{N}$, Naruse H, eds. New Trends in Neonatal Screening. SapN, Naruse H, eds. New Trends in Neonatal
poro: Hokkaido Univ Press, 1994:105-8.

poro: Hokkaido Univ Press, 1994:105-8.
8 Wallace AM, Beastall GH, Cook B, et al. Neonatal screening for congenital adrenal hyperplasia: a programme based on for congenital adrenal hyperplasia: a programme based on a novel direct radioimmunoassay
hydroxyprogesterone in blood spots. $f$ Endocrinol 1986;108:299-308

9 Suwa S, Matsuura N, Kitagawa T, et al. Results of neonatal mass-screening for congenital adrenal hyperplasia (CAH) in Japan. In: Schmidt BJ, Diamante AJ, Loghin-Grosso NS eds. Current Trends in Infant Screening. Proceedings of the Seventh International Neonatal Screening Symposium, Excerpta Medica International Congress Series. Amsterdam: Elsevier, 1989:313-18.

10 Shimozawa K, Saisho S, Saito N, et al. A neonatal mass-screening for congenital adrenal hyperplasia in Japan. Acta Endocrinol 1984;107:513-18.

11 Wallace AM, Beesley J, Thomson M, Giles CA, Ross AM, Taylor NF. Adrenal status during the first month of life in mature and premature human infants. 7 Endocrinol mature and prema

12 Lee MM, Rajagopalan L, Berg GJ, Moshang T. Serum adrenal steroid concentration in premature infants. $7 \mathrm{Clin}$ Endocrinol Metab 1989;69:1133-6.

13 Reiter EO, Fuldauer VG, Root AW. Secretion of the adrenal androgen, dehydroepiandrosterone sulfate, during normal infancy, childhood, and adolescence, in sick infants, and in children with endocrinologic abnormalities. $\mathcal{F}$ Pediatr 1977;90:766-70.

14 Murphy JF, Joyce BG, Dyas J, Hughes IA. Plasma 17-hydroxyprogesterone concentrations in ill newborn infants. Arch Dis Child 1983;58:532-4.

15 Overdiek HWPM, Hermens WAJJ, Merkus FWHM. New insights into the pharmacokinetics of spironolactone. Clin Pharmacol Ther 1985;38:469-74.

16 Mizushima Y, Fukushi M, Arai O, et al. Neonatal screening for congenital adrenal hyperplasia due to 21 -hydroxylase deficiency 2 . Analysis of steroids with high-performance liquid chromatography for diagnosis of congenital adrenal hyperplasia. Folia Endocrinol 1987;63:102-12.

17 Weisman Y, Bar A, Root A, Spider Z, Golander A. Rapid diagnosis of congenital adrenal hyperplasia by high performance liquid chromatography. Clin Chim Acta 1984;138:1-8.

18 Saisho S, Shimozawa K, Yata J. Changes of several adrenal $\Delta^{4}$-steroids measured by HPLC-UV spectrometry in neonatal patients with congenital adrenal hyperplasia due to 21-hydroxylase deficiency. Horm Res 1990;33:27-34.

19 Overdiek JWPM. Determination of the serum concentration of spironolactone and its metabolites by high-performance liquid chromatography. $\mathcal{F}$ Chromatogr 1985;341:279-85.

20 Mclnnes GT, Asbury MJ, Shelton JR, et al. Activity of sulfur-containing intermediate metabolites of spironolacsulfur-containing intermediate metabolites

21 Erbler HC. Stimulation of aldosterone production in vitro and its inhibition by spironolactone. NaunynSchmiedeberg's Arch Pharamacol 1972;273:366-75.

22 Erbler HC. On the mechanism of inhibitory action of the spironolactone SC 9376 (aldadiene) on the production of corticosteroids in rat adrenals in vitro. NaunynSchmiedeberg's Arch Pharamacol 1973;277:139-49.

23 Cheng SC, Suzuki K, Sadee W, Harding BW. Effects of spironolactone, canrenone, and canrenoate- $\mathrm{K}$ on cytochrome P450, and 18-hydroxylation in bovine and human adrenal cortical

24 Greiner JW, Kramer RE, Jarrell J, Colby HD. Mechanism of action of spironolactone on adrenocortical function in guinea pigs. f Pharmacol Experiment Therapeut 